and later confirmed by dosages of catecholamines. The institution of an early aggressive treatment was life saving.

Compared with the scheduled device implantation in patients deteriorating on the waiting list, management of emergencies requiring circulatory support is still a challenging situation. We have developed in our unit a mobile kit of emergency circulatory support to deal with this problem. This ECLS has become a useful adjunct to our cardiac assist device program, allowing patient transfer and secondary implantation of a more long-term sophisticated device.

As expected in this catecholamine-induced cardiomyopathy, the patient recovered after surgical resection of the tumor, but recovery is not so fast as to allow the use of an ECLS device alone, and implantation of a long-term device was mandatory.

\section{Conclusion}

Diagnosis and treatment of cardiogenic shock caused by pheochromocytoma is difficult and can end in fatal evolution. This case emphasizes the need for an early aggressive treatment to improve the outcome of this surgically curable pathology.

\section{References}

1. Kizer JR, Koniaris LS, Edelman JD, St John Sutton MG. Pheochromocytoma crisis, cardiomyopathy, and hemodynamic collapse. Chest. 2000;118:1221-3.

2. Mohamed HA, Aldakar MO, Habib N. Cardiogenic shock due to acute hemorrhagic necrosis of a pheochromocytoma: a case report and review of the literature. Can J Cardiol. 2003;19:573-6.

3. Liao WB, Liu CF, Chiang CW, Kung CT, Lee CW. Cardiovascular manifestations of pheochromocytoma. Am J Emerg Med. 2000;18: 622-5.

4. Dalby M, Burke M, Radley-Smith R, Banner N. Pheochromocytoma presenting after cardiac transplantation for dilated cardiomyopathy. J Heart Lung Transplant. 2001;20:773-5.

5. Grinda JM, Latremouille Ch, Chevalier P, D'Attelis N, Boughenou F, Guillemain R, et al. Bridge to transplantation with the DeBakey VAD axial pump: a single center report. Eur J Cardiothorac Surg. 2002;22: 965-70.

\title{
Percutaneous occlusion of a pseudoaneurysm evolving after homograft aortic valve and root replacement with the Amplatzer muscular ventricular septal defect occluder
}

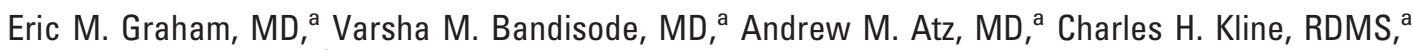

Marian H. Taylor, MD, ${ }^{b}$ and John S. Ikonomidis, MD, PhD, ${ }^{c}$ Charleston, SC

A ortic root replacement with aortic homograft has yielded good results in appropriate patients. Aortic pseudoaneurysms are a rare postoperative complication, potentially leading to reoperation with significantly higher surgical mortality. ${ }^{1}$ We describe a case in which a left ventricular outflow tract pseudoaneurysm is successfully occluded with transcatheter device closure in a patient at high risk for reoperation.

\section{Clinical Summary}

A 40-year-old woman presented with a history of a bicuspid aortic valve with severe insufficiency, ascending aortic aneurysm, and hemiarch aneurysm. After discussion of the various treatment options, she

\footnotetext{
From the Divisions of Pediatric Cardiology, ${ }^{\mathrm{a}}$ Cardiology, ${ }^{\mathrm{b}}$ and Cardiothoracic Surgery, ${ }^{\mathrm{c}}$ Medical University of South Carolina, Charleston, SC.

Received for publication Nov 8, 2005; accepted for publication Nov 15, 2005.

Address for reprints: Varsha M. Bandisode, MD, Medical University of South Carolina, 165 Ashley Ave, PO Box 250915, Charleston, SC 29425 (E-mail: bandisvm@musc.edu).

J Thorac Cardiovasc Surg 2006;131:914-6

$0022-5223 / \$ 32.00$

Copyright $\odot 2006$ by The American Association for Thoracic Surgery doi:10.1016/j.jtcvs.2005.11.016
}

underwent surgical replacement with a 22-mm homograft aortic valve, root, and ascending aorta. Her midterm postoperative course was complicated by gram-negative endocarditis and dehiscence of the homograft. Her aortic homograft was rereplaced 22 days after initial intervention and was complicated by uncontrollable bleeding from a posterior annular suture line. An anterior pericardial baffle was created and decompressed to the right atrial appendage, resulting in hemostasis. At 48 days after the second surgical intervention, follow-up revealed a persistent and increasing left-to-right shunt. At surgical re-exploration, an unsuccessful attempt (caused by continued bleeding) was made to repair the homograft at the posterior annulus, requiring replacement of the pericardial baffle.

Serial computed tomographic angiography revealed closure of the left-to-right shunt, but a contained pseudoaneurysm remained in the lateral aspect of the left ventricular outflow tract directed posteriorly between the left atrium and the aortic arch and draped by the left main coronary artery. Serial evaluations revealed progressive enlargement of the pseudoaneurysm with tenting of the left main coronary artery at its bifurcation.

Given her multiple reoperations, she was referred for transcatheter device occlusion of the pseudoaneurysm. Institutional review board approval for compassionate use of the device, as well as informed consent, was obtained. Transthoracic echocardiography revealed a $3.5 \times 1.6-\mathrm{cm}$ pseudoaneurysm located posteriorly and leftward of the aortic valve. The neck to the pseudoaneurysm originated under the aortic valve within the left ventricular outflow 


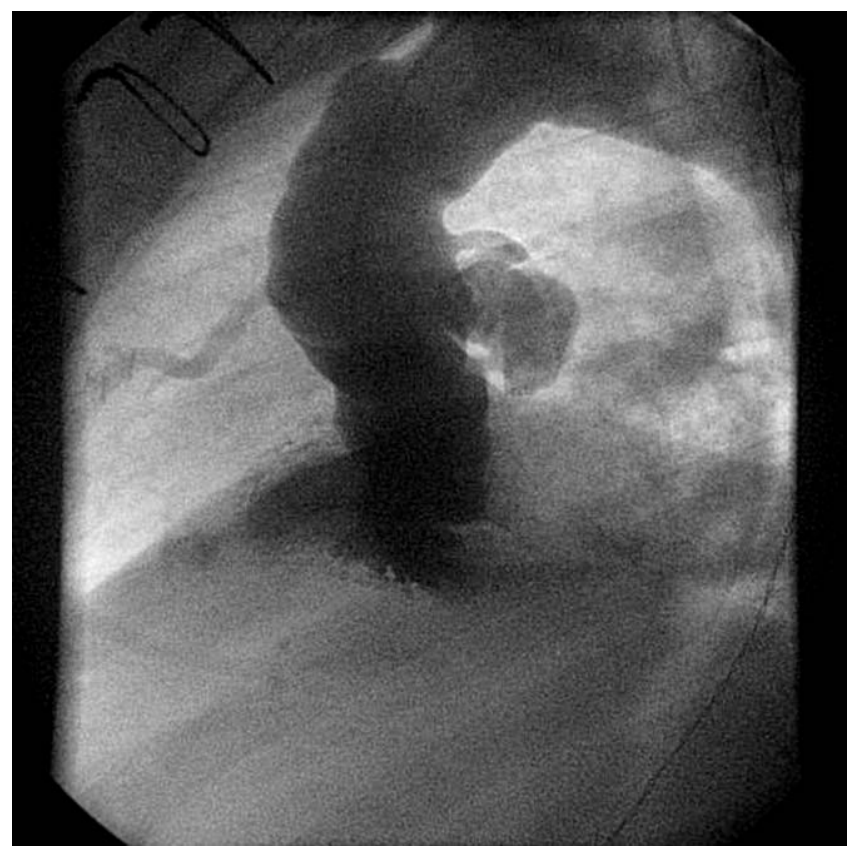

Figure 1. Left ventricular pseudoaneurysm with draping Left Coronary Artery.

tract. The distance between the homograft aortic valve, the anterior mitral leaflet hinge point, and the neck of the pseudoaneurysm was 6 and $7 \mathrm{~mm}$, respectively.

A right and left heart catheterization was performed by using the right femoral vein and artery, respectively with selective angiography of the left ventricle, aortic root and coronary arteries. A 5F 100-cm JR 3.5 catheter (Cook, Bloomington, Ind) was advanced retrogradely from the femoral artery into the left ventricle, and the pseudoaneurysm was engaged. Angiography of the pseudoaneurysm revealed the neck measured $3.5 \mathrm{~mm}$ in diameter, with tenting of the left main coronary artery (Figure 1). Standard device delivery sheaths provided inadequate length for stable sheath placement and device deployment. An 8F SL2 transseptal sheath (St Jude Medical, Inc, Minnetonka, Minn) was loaded with a 7F IB catheter (Boston Scientific, Natick, Mass), with stable position in the pseudoaneurysm. A 4-mm Amplatzer muscular ventricular septal defect occluder device (AGA Medical, Golden Valley, Minn) was placed in the neck of the pseudoaneurysm with transesophageal echocardiographic guidance. The distal disk was deployed in the aneurysm, and the device waist was deployed in the aneurismal neck. The proximal disk was deployed on the ventricular aspect of the subvalvar aortic root. Obliteration of blood flow into the pseudoaneurysm was noted by means of echocardiography and angiography (Figure 2). No change in aortic or mitral valve function was observed. The postprocedure recovery was uneventful, with extubation in the catheterization laboratory, an overnight observation, and subsequent discharge the following morning without complications. Transthoracic echocardiography and computed tomographic angiographic studies performed 1 month after the procedure confirmed complete occlusion of the pseudoaneu-

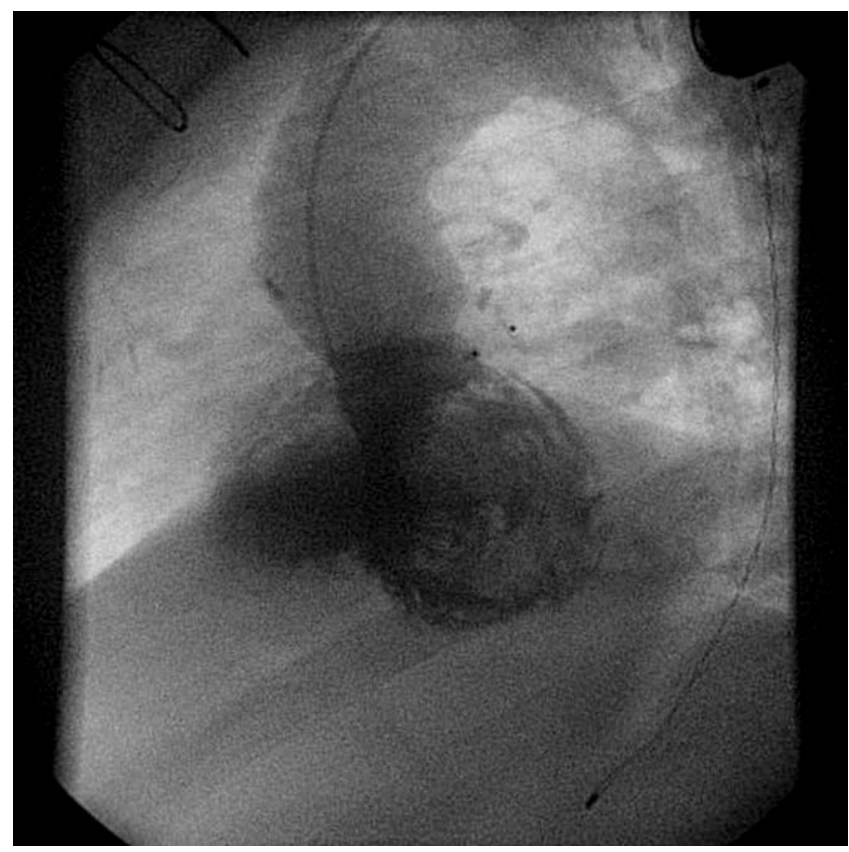

Figure 2. Complete occlusion of pseudoaneurysm with Amplatzer Muscular Occluder Device.

rysm with resolving hematoma, no change in aortic or mitral valve function, and no residual tenting of the left coronary artery.

\section{Discussion}

Pseudoaneurysm formation after aortic root replacement is a postoperative complication that has traditionally been addressed by surgical means. Reoperation increases both the difficulty for exposure of the surgical field caused by scar tissue and surgical mortality.

Reports of percutaneous occlusion of aortic aneurysms have been described by using balloon occlusion to facilitate elective surgical repair ${ }^{2}$ and coil embolization. ${ }^{3,4}$ The recent success with an Amplatzer septal occluder device in a pulmonary aneurysm in a patient with tetralogy of Fallot and Eisenmenger syndrome confirms the utility of device closure in patients unsuited to standard surgical intervention. ${ }^{5}$ We describe an unconventional use of the Amplatzer muscular ventricular septal defect occluder device for transcatheter closure of an aortic pseudoaneurysm with minimal risk and early complete closure.

\section{References}

1. Kaya A, Schepens MA, Morshuis WJ, Heijmen RH, Brutel de la Riviere A, Dossche KM. Valve-related events after aortic root replacement with cryopreserved aortic homografts. Ann Thorac Surg. 2005;79:1491-5.

2. Henriques JP, Brutel de la Riviere A, Schepens MA, Ernst JM. Percutaneous occlusion of the entry to a leaking false aneurysm after ascending aortic replacement for aortic dissection type A facilitating surgical repair. Eur J Cardiothorac Surg. 1997;11:381-3.

3. Miguel B, Camilleri L, Gabrillargues J, Macheda B, Kubota H, Ravel A, et al. Coil embolization of a false aneurysm with aorto-cutaneous fistula after prosthetic graft replacement of the ascending aorta. Eur J Radiol. 2000;34:57-9.vlk 
4. Chapot R, Aymard A, Saint-Maurice JP, Bel A, Merland JJ, Houdart E. Coil embolization of an aortic arch false aneurysm. J Endovasc Ther. 2002;9:922-5.
5. Pate GE, Carere RG. Percutaneous occlusion of a pulmonary aneurysm causing hemoptysis in a patient with pulmonary atresia and aortopulmonary collaterals. Catheter Cardiovasc Interv. 2005;65:310-2.

\section{Congenital bronchoesophageal fistula in an adult woman}

Rafael Aguiló, MD, PhD, ${ }^{a}$ Juan Minguella, MD, PhD, ${ }^{a}$ Jaime Jimeno, MD, ${ }^{a}$ Sonia Puig, MD, ${ }^{a}$ José A. Galeras, MD, Angel Gayete, MD, PhD, ${ }^{\mathrm{c}}$ and José M. Sánchez-Ortega, MD, PhD, ${ }^{a}$ Barcelona, Spain

$\mathrm{T}$

racheoesophageal or bronchoesophageal fistula (T/BEF), the abnormal communication between the esophagus and the tracheobronchial tree, may present at any time during the life span. In the neonate, T/BEF is a congenital malformation associated with some form of esophageal atresia in the vast majority of cases. ${ }^{1,2}$ Later in life, most T/BEFs are acquired. ${ }^{3,4}$ However rare, if the congenital T/BEF is not associated with esophageal atresia, it may remain silent until it eventually becomes symptomatic. Herein, we report the clinical case of a 53-year-old woman whose congenital T/BEF was diagnosed and treated at our institution.

\section{Clinical Summary}

The patient was referred to us as a result of a self-limited episode of minor hemoptysis of sudden onset. At anamnesis, she explained that she had experienced a pain in the upper abdomen 2 years before. Gallbladder stone disease and unilateral renal agenesia were diagnosed by echography, and chronic gastritis was diagnosed by esophagogastroscopy. She was then cholecystectomized without postoperative complications. She did not disclose any other previous disease or complaint. Physical examination was normal on admission. Red blood cell, white blood cell, and platelet counts, coagulation profile; routinary serum; and urine analysis results were all within the normal range. Chest radiography and a computed tomographic scan of the thorax displayed an irregular area of lung parenchyma condensation in the upper segment of the left lower lobe. On fiberoptic bronchoscopy, the tracheobronchial tree was normal except for the presence of a blood clot that partly occupied the lumen of the left lower lobe bronchus. Bronchial washing specimens were sent for cytologic analysis, Gram and acid-fast stain, and bacterial and mycobacterial culture; all yielded

From the Servei de Cirurgia General, Abdominal, i Toràcica, ${ }^{\text {a }}$ Unitat d'Endoscòpia Digestiva, ${ }^{\mathrm{b}}$ and Unitat de Diagnòstic per l'Imatge, ${ }^{\mathrm{c}}$ Hospital del Mar, Institut Municipal d'Assitència Sanitària, Barcelona, Spain.

Received for publication Sept 30, 2005; accepted for publication Oct 26, 2005.

Address for reprints: Rafael Aguiló, MD, PhD, Servei de Cirurgia General, Abdominal, i Toràcica, Hospital del Mar, Institut Municipal d'Assitència Sanitaria, Barcelona, Spain (E-mail: 95183@imas.imim.es).

J Thorac Cardiovasc Surg 2006;131:916-7

$0022-5223 / \$ 32.00$

Copyright $@ 2006$ by The American Association for Thoracic Surgery doi:10.1016/j.jtcvs.2005.10.054

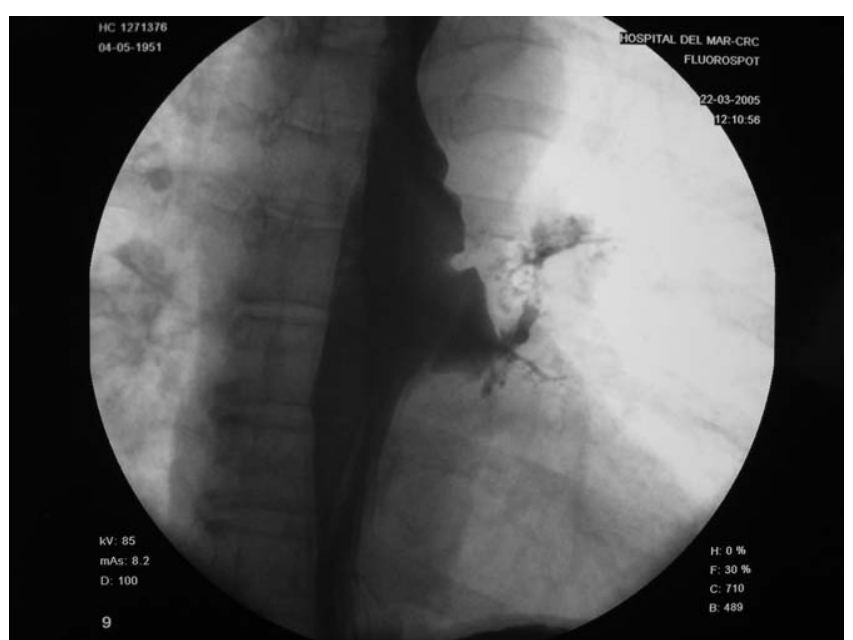

Figure 1. Preoperative esophagogram. The contrast medium passes from a diverticulum in the middle esophagus through an ascending fistula to the left lower lobe bronchus.

negative results. Esophagogastroduodenoscopy revealed the presence of a double hole in the left wall of the middle esophagus. Bouts of cough ensued every time the holes were instilled with serum saline, thus establishing the diagnosis of T/BEF. Initial treatment consisted of full oral fasting and total enteral nutrition for 3 weeks. Then, an attempt was made to close the fistula by endoscopic instillation of fibrin glue. However, an esophagogram showed the persistence of the T/BEF (Figure 1), and the patient was scheduled for an open surgical procedure. Dissection of the fistula, closure of both ends with an automatic stapler, division of the tract, handmade reinforcement of both sutures, and interposition of a pedicled pleural flap were performed through a left posterolateral thoracotomy. Postoperative evolution was normal. A second esophagogram showed no spilling of the contrast. The patient restarted oral feeding on the sixth postoperative day.

\section{Comment}

Congenital T/BEF seldom presents in adulthood because it is rarely left undiagnosed in the neonate: it is often associated with some other bronchopulmonary and/or foregut malformation (mainly with esophageal atresia). ${ }^{1,2}$ It is only in the absence of this 